\title{
Mass administration of the antimalarial drug mefloquine to Guantánamo detainees: a critical analysis
}

\author{
Remington L. Nevin \\ Department of Preventive Medicine, Bayne-Jones Army Community Hospital, Ft. Polk, LA, USA
}

\begin{abstract}
Recently, evidence has emerged from an unusual form of mass drug administration practised among detainees held at US Naval Station Guantánamo Bay, Cuba ('Guantánamo'), ostensibly as a public health measure. Mefloquine, an antimalarial drug originally developed by the US military, whose use is associated with a range of severe neuropsychiatric adverse effects, was administered at treatment doses to detainees immediately upon their arrival at Guantánamo, prior to laboratory testing for malaria and irrespective of symptoms of disease. In this analysis, the history of mefloquine's development is reviewed and the indications for its administration at treatment doses are discussed. The stated rationale for the use of mefloquine among Guantánamo detainees is then evaluated in the context of accepted forms of population-based malaria control. It is concluded that there was no plausible public health indication for the use of mefloquine at Guantánamo and that based on prevailing standards of care, the clinical indications for its use are decidedly unclear. This analysis suggests the troubling possibility that the use of mefloquine at Guantánamo may have been motivated in part by knowledge of the drug's adverse effects, and points to a critical need for further investigation to resolve unanswered questions regarding the drug's potentially inappropriate use.
\end{abstract}

keywords malaria, mefloquine, military medicine, United States, Cuba

\section{Introduction}

Evidence has recently emerged (Denbeaux et al. 2010; Leopold \& Kaye 2010; Shane 2011) from an unusual form of mass drug administration (MDA) practised among detainees held at US Naval Station Guantánamo Bay, Cuba ('Guantánamo'). Documents released in 2007 by the Department of Defense (DoD), in response to a Freedom of Information Act (FOIA) request, indicate that many, if not all, of the detainees held at the facility received treatment doses of the antimalarial drug mefloquine immediately upon their arrival to Guantánamo (DoD 2007). Although the island is currently free of malaria, competent vectors for disease transmission (Bawden et al. 1995) including Anopheles albimanus (Molina-Cruz et al. 2004) still exist. Thus, the migration into Cuba of individuals infected with malaria creates a theoretical risk of reintroduction via autochthonous transmission. Most of the detainees held at Guantánamo had been captured from malaria-endemic countries. Mefloquine treatment as a public health measure was ostensibly motivated by a desire to prevent such reintroduction.

Individual detainee medical records and the 'Standard Inprocessing Orders for Detainees' contained within the
FOIA release (Figure 1) indicate that mefloquine was administered by mouth ('PO') upon arrival, at treatment doses of $1250 \mathrm{mg}$ ('750 mg PO now, $500 \mathrm{mg}$ PO in 12 h') (DoD 2007) before laboratory testing for malaria and irrespective of the presence of symptoms of disease. Representatives from DoD have recently defended this practice by claiming that '[a]llowing the disease to spread would have been a public health disaster' (Shane 2011) and contending that this MDA was therefore 'completely appropriate' (Shane 2011). Others have concluded that this use of mefloquine was medically inappropriate at best, and at worst constituted a form of abuse (Denbeaux et al. 2010; Leopold \& Kaye 2010).

This analysis reviews the history of mefloquine's development and discusses indications for the administration of treatment doses of antimalarial drugs including mefloquine. The stated rationale for the use of mefloquine among Guantánamo detainees is evaluated in the context of accepted forms of population-based malaria control. Possible indications for the use of mefloquine at Guantánamo are discussed, and recommendations made for further investigation to resolve critical unanswered questions regarding the drug's use. 
R. L. Nevin Administration of mefloquine to Guantánamo detainees

\begin{tabular}{l|l}
\hline Health record & \multicolumn{1}{c}{ Chronological record of medical care } \\
\hline Date & Symptoms, Diagnosis, Treatment, Treating organization (Sign each page) \\
\hline & $\begin{array}{l}\text { JTF, JMG, Medical Department, Guantanamo Bay, Cuba } 09593 \\
\text { (updated 24 September 2003//sed) }\end{array}$ \\
& Standard inprocessing orders for detainees: \\
& 1. Mefloquine $750 \mathrm{mg}$ PO now, $500 \mathrm{mg} \mathrm{PO}$ in $12 \mathrm{~h}$
\end{tabular}

Figure I Extract of 'Standard Inprocessing Orders for Detainees' (from DoD 2007).

\section{History of mefloquine's development and use}

Mefloquine is a 4-methanolquinoline structurally related to quinine. US military scientists at the Walter Reed Army Institute of Research (WRAIR) developed the compound in the early 1970s in response to concerns of rising chloroquine resistance (United Nations Development Programme (UNDP) et al. 1983). Initially known as WR142,490, the drug underwent Phase I testing on US prisoners (Alving et al. 1948) beginning in 1972 (Trenholme et al. 1975; UNDP et al. 1983) and Phase II testing for treatment (Maugh 1977) and prophylaxis (Clyde et al. 1976) of malaria throughout the 1970s (Pearlman et al. 1980) and early 1980s (UNDP et al. 1983). Following initial testing, the drug was transferred to F. Hoffmann-La Roche Ltd. for commercial development (Fernex 1981), where it was given the trade name Lariam ${ }^{\circledR}$. The drug had initially proven highly effective against the illness-causing bloodstage schizonts of chloroquine-resistant Plasmodium falciparum and P. vivax (Clyde et al. 1976), but was later shown to lack the effectiveness of the related 8-aminoquinolines against liver-stage schizonts and hypnozoites, and against the blood-stage gametocytes that transmit the disease (Karbwang et al. 1992; Price et al. 1999).

During initial testing, transient dizziness and nausea were reported at high treatment doses of 1750-2000 mg (Trenholme et al. 1975). During subsequent testing, lower treatment doses ranging from 750-1500 mg were also found to carry a risk of nausea, abdominal pain and explosive vomiting (Hall et al. 1977), as well as central nervous system (CNS) adverse effects including dizziness (de Souza 1983; Kofi Ekue et al. 1983) and 'giddiness' (Tin et al. 1982). Evidence later emerged of a risk of severe behavioural disturbance (Kofi Ekue et al. 1983) associated with the use of mefloquine including disorientation (UNDP et al. 1983) and psychosis (Harinasuta et al. 1983). Soon after the initial European licensure of mefloquine in 1985 , confusion (Björkman 1989; Rouveix et al. 1989), amnesia (Castot \& Garnier 1988; Lapras et al. 1989), loss of mental focus and an inability to concentrate (Patchen et al. 1989) were not uncommonly reported. Symptoms of often debilitating dizziness and vertigo were also reported
(Patchen et al. 1989) and were later demonstrated to affect a majority of healthy adults with use at treatment doses (Rendi-Wagner et al. 2002).

Notwithstanding early concerns from the World Health Organization (WHO) of severe CNS reactions including hallucinations, depression and suicidal behaviour associated with its use (WHO 1989), mefloquine was approved by the US Food and Drug Administration (FDA) for prophylaxis of malaria and was soon widely prescribed among US military personnel at a weekly dose of $250 \mathrm{mg}$ (Wallace et al. 1996; Nevin 2010; Whitman et al. 2010). In the years since the drug's approval, awareness has grown of an unexpectedly high risk of CNS adverse effects (Overbosch et al. 2001), as well as the potential for neurotoxicity (Dow et al. 2003, 2006; Hood et al. 2010) and associated long-term adverse effects (Nevin 2012) with use even at this lower prophylactic dose. This risk is thought to be increased among those with a history of mental illness or other CNS contraindication (Nevin et al. 2008).

Despite administrative policies (Department of the Army Office of the Surgeon General 2002) and restrictive labelling changes intended to reduce the risk of adverse effects, inappropriate prescribing of the drug has remained widespread (Nevin 2010; Office of the Assistant Secretary of Defense for Health Affairs (OASDHA) 2012). In response, the US military has now sharply restricted the drug's use (OASDHA 2009) amid new concerns that the CNS adverse effects of mefloquine might also complicate the diagnosis and management of post-traumatic stress disorder and other neuropsychiatric conditions associated with combat (Magill et al. 2011).

Mefloquine is no longer considered the drug of choice for the treatment of malaria; the WHO now recommends only artemisinin-based combination therapies (ACTs), particularly artemisinin-lumefantrine (marketed in the USA as Coartem ${ }^{\circledR}$ ) (WHO 2010). ACTs containing mefloquine, while effective, are controversial owing to the concerns of potential synergistic neurotoxicity and poor tolerability (Toovey 2009; WHO 2010). Similarly, mefloquine is decreasingly utilised for prophylaxis among civilian travellers in favour of safer and better-tolerated 
R. L. Nevin Administration of mefloquine to Guantánamo detainees

antimalarial medications (LaRocque et al. 2011). Lariam ${ }^{\circledR}$ was recently withdrawn from the US market without explanation (Strauch et al. 2011), although generic formulations of mefloquine remain available.

\section{Indications for use of antimalarial drugs at treatment doses}

Unlike their widespread use in prophylaxis, the administration of treatment doses of antimalarial medications to individuals without confirmation of disease is typically undertaken only for very specific indications. As all available drugs, and particularly mefloquine, are associated with an increased risk of toxicity and adverse effects when administered at treatment doses as compared to at lower, prophylactic doses (WHO 2001), such use must very carefully balance potential individual and population benefits against these risks. Historically, forms of such treatment have included MDA (von Seidlein \& Greenwood 2003; Greenwood 2010), intermittent preventive treatment (IPT) (Greenwood 2010) and empiric treatment, with only IPT today remaining a critical component of global malaria control efforts (WHO 2004).

Primarily used to attempt eradication of malaria from a defined geographical region, MDA involves the universal administration of antimalarial treatment doses irrespective of infection status (Greenwood 2004). This is best accomplished by encouraging all individuals in the defined region to accept treatment that targets not only the illnesscausing blood-stage schizonts, but also gametocytes and liver-stage hypnozoites in areas where relapsing $P$. vivax or $P$. ovale is prevalent. A potentially strong method in theory, MDA has achieved only modest success in practice (von Seidlein \& Greenwood 2003; Greenwood 2004). Some believe that a more viable role for MDA may be in the final stages of geographical eradication efforts, using gametocidal and hypnozoiticidal primaquine or the newer 8-aminoquinoline agents (Greenwood 2010).

Intermittent preventive treatment, which is also occasionally referred to as intermittent presumptive treatment (White 2005), is the practice of universally administering treatment doses to asymptomatic individuals who are at increased risk of morbidity or mortality from disease (Milner et al. 2010). In practice, IPT differs from MDA by targeting treatment to specific and individual patient risk factors, rather than solely to geographical location. A large body of evidence supports the benefits of IPT among pregnant women (IPTp), particularly the use of the generally well-tolerated drug combination sulphadoxine/pyrimethamine (SP) (Sirima et al. 2006; Greenwood 2010). Growing concerns of antimalarial resistance (Nosten et al. 2003; White 2005), however, are placing a higher priority on screening for infection prior to treatment (Tagbor et al. 2010). Similarly, in an example of IPT targeted to travellers (IPTt), individuals returning from prolonged exposure in areas endemic for $P$. vivax or $P$. ovale are frequently prescribed gametocidal and hypnozoiticidal primaquine (Oliver et al. 2008; Burgoine et al. 2010 ) in a treatment referred to as presumptive antirelapse therapy (PART), but only after testing for a contraindicating glucose-6-phosphate dehydrogenase (G6PD) enzyme deficiency (Hill et al. 2006).

Empiric treatment is the controversial practice of routinely administering antimalarial treatment doses to symptomatic individuals from populations with a high prevalence of disease, who are in settings with limited diagnostic capacity (Parikh et al. 2010). Unlike in MDA or IPT, empiric treatment presumes malaria disease based on a perceived high predictive value of appropriate clinical symptoms, such as fever. Empiric treatment has fallen out of favour in the context of rising concerns of risk associated with the indiscriminate use of antimalarials (Parikh et al. 2010; WHO 2010). Efforts at global malaria control now emphasise expanding diagnostic capacity through rapid diagnostic tests (RDT) (WHO 2010), to permit confirmation of disease prior to targeted treatment.

\section{Rationale for the use of mefloquine at Guantánamo}

The mass administration of mefloquine at treatment doses to detainees at Guantánamo does not correspond well with any of these three indications. True MDA involves a universal administration of treatment designed to eradicate any potential source of infection, yet not all individuals arriving at Guantánamo received treatment consistent with MDA. Investigative news reports suggest that South Asian contractor personnel, hired to work on construction projects at Guantánamo, and arriving from malariaendemic areas, were not administered mefloquine at treatment doses (Kaye \& Leopold 2011).

Empiric treatment, involving a selective use of antimalarials guided by symptoms, is generally motivated by cost or diagnostic limitations. Neither was a factor at Guantánamo. All detainees had regular access to medical care and received a comprehensive medical evaluation upon arrival, which included assessment of vital signs (Figure 2) and thick and thin-smear microscopic testing for malaria. These smears were first screened at the Guantánamo Bay Naval Hospital and then sent for confirmation to Naval Hospital Portsmouth, Virginia (DoD 2007).

While inconsistent with either true MDA or empiric treatment, the mass administration of mefloquine to Guantánamo detainees might arguably conform to a type of IPTt referred to as post-arrival (or pre-departure) 
R. L. Nevin Administration of mefloquine to Guantánamo detainees

NURSING

7. Vitals are done \& medications are given (Mefloquine, Albendazole) before the detainee leaves the exam room.

8. Tetanus and influenza vaccines are administered and PPD placed on forearm

9. Height and weight taken and recorded (BMI calculated later).

10. Radiologist reads chest $x$-ray before detainee leaves the building and if'No Active Disease' (NAD) noted surgical face mask may be removed and disposed of. Also remove the scopolamine patch from behind ear (used to prevent airsickness during transit).

11. Perform quality assurance check on medical record. Verify that the detainee has stopped at each station, by checking the tracking sheet, before allowing the detainee's departure.

12. Detainee leaves the building through the medical side exit escorted by 2 MP's.

Figure 2 Extract of 'Nursing Standard Operating Procedures for Detainees' (from DoD 2007).

presumptive treatment (PPT). PPT is frequently justified, particularly among refugees and other dislocated populations to which detainee populations might be compared (Stauffer et al. 2008). Among the motivations for administering PPT to dislocated persons arriving in the USA is that such patients typically face barriers to accessing medical care after their arrival and that US clinicians may have limited clinical experience with malaria, thus contributing to delays in diagnosis (Phares et al. 2011). Neither of these rationales should be applicable among detainees held at Guantánamo, where ample and timely medical care was presumably available, provided by military healthcare providers familiar with the clinical and laboratory diagnosis and management of the disease (Scsepko 2002, DoD 2007).

Additionally, the Centers for Disease Control and Prevention (CDC) specifically recommends against the practice of PPT among populations relocated from outside sub-Saharan Africa (CDC 2010), noting that among this group, 'the risk and cost of post-arrival presumptive treatment currently outweighs the potential benefits'. According to an analysis of US military documents contained in the Wikileaks Guantánamo files (Scheinkman et al. 2012), a substantial majority of detainees were captured from areas of low malaria transmission intensity, including Pakistan, Afghanistan and Yemen (Matisz et al. 2011). In accordance with CDC recommendations, PPT would not be routinely indicated for these individuals.

Even among individuals from areas of sub-Saharan Africa, for whom the practice of PPT may be appropriate, CDC has previously recommended SP (CDC 2010) for this purpose. CDC later recommended the drug combination atovaquone/proguanil, marketed and widely available in the USA since 2000 as Malarone ${ }^{\circledR}$, which was noted to be 'generally well tolerated with few adverse effects' (CDC 2010). The CDC has noted that 'other available medications have higher rates of adverse effects (e.g. mefloquine)'
(CDC 2010), and a military author at WRAIR has commented that '[w]ith the availability of better-tolerated drugs, there is no need to use mefloquine for treatment unless other options are unavailable' (Magill 2006).

Absent a highly improbable shortage of such bettertolerated drugs, the indication for the use of mefloquine at Guantánamo, in what appears to be a questionable application of PPT, is therefore decidedly unclear. The use of mefloquine for this purpose finds no precedent in the literature on PPT (Slutsker et al. 1995; Miller et al. 2000; Barnett 2004; CDC 2010), and researchers at WRAIR have even emphasised that mefloquine will 'likely not find use' for this indication among 'asymptomatic, otherwise healthy' persons 'due to its association with adverse CNS events at therapeutic doses' (Milner et al. 2010). Today, in conformity with WHO recommendations, the treatment of choice for PPT is the ACT Coartem ${ }^{\circledR}$ (Phares et al. 2011).

\section{Use of mefloquine as a public health measure}

The primary justification for the use of PPT has typically been on clinical grounds and not for public health purposes. Despite posing a theoretical risk of autochthonous transmission, no local cases of malaria transmission have been linked to refugee resettlement in the USA (Phares et al. 2011). Yet statements from US military officials clearly indicate that the motivation for the use of mefloquine at Guantánamo was not clinical, but was 'entirely for public health purposes to prevent the introduction of malaria to the Guantánamo area' (Shane 2011). Mefloquine, however, is a schizonticide and clearly not well suited for this indication (UNDP et al. 1983; Price et al. 1999). Although effective at curing acute infection, mefloquine is incompletely effective against the mature gametocytes that transmit disease (Price et al. 1999). Its use would therefore be insufficient to guarantee prevention of autochthonous transmission in the presence of competent vectors. The 
R. L. Nevin Administration of mefloquine to Guantánamo detainees

8-aminoquinoline primaquine, also administered to detainees after laboratory testing for G6PD deficiency (DoD 2007), would alone have been sufficient for this indication, given its more effective gametocidal properties (Tagbor et al. 2010).

While competent vectors for the transmission of malaria are indeed found on the island of Cuba (MolinaCruz et al. 2004; Gutiérrez et al. 2009), concurrent vector control methods were in use at Guantanamo during the time that mefloquine was being administered. A US military publication noted that an aggressive mosquito surveillance programme was underway at Guantánamo as early as January 2002, with mosquito counts obtained every other day to guide insecticide spraying (Scsepko 2002). This publication even emphasised that the specific environment at Guantánamo was a 'strong force working against mosquitoes', and quoted a military physician who commented that ' $[t]$ he arid, hot environment here is not mosquito-friendly, unlike the other side of Cuba where is rains all the time' (Scsepko 2002).

The mass administration of mefloquine to detainees at Guantánamo, ostensibly as a public health measure, also contrasts oddly with methods of malaria control employed a decade earlier in a comparable setting. In 1991, in response to a sudden wave of immigration from Haiti, US military officials quickly housed over 14000 potentially infected refugees in temporary camps at Guantánamo (Bawden et al. 1995). Despite a comparable malaria risk, mass administration of antimalarials was never employed as a management strategy. Instead, military physicians and malaria experts managing the camps correctly observed that ' $\mathrm{t}$ ] o prevent transmission from immigrants to the indigenous human population, a vector surveillance and control programme is vital'. In apparent disagreement with the use of PPT, these experts further noted that at Guantánamo, 'the best strategy for handling malaria in displaced persons from an endemic area was early laboratory diagnosis or, if necessary, presumptive clinical diagnosis, and prompt treatment' (Bawden et al. 1995). It is unclear, then, why the introduction of only a few hundred (Leopold \& Kaye 2010; Scheinkman et al. 2012) potentially infected detainees would prompt the abandonment of this successful approach.

\section{Conclusions}

This analysis raises many intriguing questions regarding the precise indications for the use of mefloquine among Guantánamo detainees. While the mass administration of the drug to Guantánamo detainees may have been ratio- nally motivated for other purposes, the claim that prevention of malaria transmission was among them is firmly refuted.

One possibility is that the use of mefloquine was simply erroneously directed by senior US military medical officials overly confident of the drug's safety and unfamiliar with its appropriate use, in an apparent foreshadowing of its later, broader misprescribing among US military personnel (Nevin 2010). Another possibility, which is deeply troubling to consider, is that the decision to administer the drug was informed and motivated at least in part by knowledge of the drug's adverse neuropsychiatric effects and the presumed plausible deniability of claims of misuse in the context of its seemingly legitimate clinical or public health indication.

Unfortunately, available documentation from a meeting held by senior US health officials to discuss malaria control among Guantánamo detainees provides little insight into this decision (Leopold \& Kaye 2010). The transcript from a February 2002 meeting of the Armed Forces Epidemiological Board (AFEB) discussing the care of detainees references only the use of primaquine in the context of reducing autochthonous transmission, but makes no mention of mefloquine (AFEB 2002). Regardless, the recent justification offered by US military representatives for the mass administration of mefloquine to Guantánamo detainees suggests that the practice is familiar to current and senior US military medical officials (Shane 2011).

Further formal investigation may yet reveal the precise rationale and motivation for the use of mefloquine among Guantánamo detainees. As the actions of junior medical personnel assigned to Guantánamo come under increased ethical and legal scrutiny (Iacopino \& Xenakis 2011), the actions of senior medical leaders involved in formulating and overseeing detainee mefloquine policy must bear comparable examination.

\section{Disclaimer}

The views expressed in this article are those of the author alone and do not necessarily reflect the official policies or positions of the Department of the Army, Department of Defense or the US Government. The author is a US Army preventive medicine physician who in a private capacity has commented critically on the issues described in this analysis and who has communicated with other authors investigating and reporting on this issue (Denbeaux et al. 2010; Leopold \& Kaye 2010; Kaye \& Leopold 2011). The US Army had no role in the decision to publish or in the preparation of this manuscript (Furlow 2011). 


\section{R. L. Nevin Administration of mefloquine to Guantánamo detainees}

\section{Acknowledgements}

The author acknowledges the research assistance of Cecelia Higginbotham of the Bayne-Jones Army Community Hospital Medical Library; and Jason Leopold, Jeffrey Kaye and Mark Denbeaux for raising public awareness of the contents of the documents referenced in this report.

\section{References}

Alving A, Craige B, Pullman T, Whorton CM, Jones R \& Eichelberger L (1948) Procedures used at Stateville penitentiary for the testing of potential antimalarial agents. The Journal of Clinical Investigation 27, 2-5.

Armed Forces Epidemiological Board (AFEB) (2002) February 19, 2002 Meeting Minutes, San Diego, California. Available at: http://www.health.mil/dhb/afeb/meeting/Transcripts/Day1Tran scripts.pdf (accessed 21 June 2012).

Barnett ED (2004) Infectious disease screening for refugees resettled in the United States. Clinical Infectious Diseases 39, 833-841.

Bawden MP, Slaten DD \& Malone JD (1995) Falciparum malaria in a displaced Haitian population. Transactions of the Royal Society of Tropical Medicine and Hygiene 89, 600-603.

Björkman A (1989) Acute psychosis following mefloquine prophylaxis. Lancet 2, 865.

Burgoine KL, Bancone G \& Nosten F (2010) The reality of using primaquine. Malaria Journal 9, 376.

Castot A \& Garnier R (1988) [Consideration of the side effects of mefloquine: a medico-surgical consultation]. Le Concours Médical 198, 4003.

Centers for Disease Control and Prevention (CDC) (2010) Presumptive treatment of $P$. falciparum malaria in refugees relocating from sub-Saharan Africa to the United States. Available at: http://www.cdc.gov/immigrantrefugeehealth/guidelines/ domestic/malaria-guidelines-domestic.html (accessed 21 June 2012).

Clyde DF, McCarthy VC, Miller RM \& Hornick RB (1976) Suppressive activity of mefloquine in sporozoite-induced human malaria. Antimicrobial Agents and Chemotherapy 9, 384-386.

de Souza JM (1983) A phase I clinical trial of mefloquine in Brazilian male subjects. Bulletin of the World Health Organization 61, 809-814.

Denbeaux M, Camoni S, Beroth B et al. (2010) Drug abuse: an exploration of the government's use of mefloquine at Guantanamo. Available at: http://law.shu.edu/ProgramsCenters/PublicInt GovServ/policyresearch/upload/drug-abuse-explorationgovernment-use-mefloquine-gunatanamo.pdf (accessed 21 June 2012).

Department of Defense (DoD) (2007) Detainee Hospital Guantanamo Bay Cuba Standard Operating Procedures (SOPs), Operational Policy Memorandums concerning health care, Behavioral Science Consultation Team (BSCT) SOPs. Available at: http://www.dod.mil/pubs/foi/operation_and_plans/Detainee/ GITMO_MedicalSOPs.pdf (accessed 21 June 2012).
Department of the Army Office of the Surgeon General. (2002) Memorandum: updated health care provider information on use of mefloquine hydrochloride (Lariam $\left.{ }^{\circledR}\right)$ for malaria prophylaxis. Available at: http://www.pdhealth.mil/downloads/ Mefloquine_Hyrochloride_Use.pdf (accessed 21 June 2012).

Dow GS, Hudson TH, Vahey M \& Koenig ML (2003) The acute neurotoxicity of mefloquine may be mediated through a disruption of calcium homeostasis and ER function in vitro. Malaria Journal 2, 14.

Dow G, Bauman R, Caridha D et al. (2006) Mefloquine induces dose-related neurological effects in a rat model. Antimicrobial Agents and Chemotherapeutics 50, 1045-1053.

Fernex M (1981) [Urgent need to develop new antimalarials]. Schweizerische Rundschan für Medizin Praxis 70, 1025-1032.

Furlow B (2011) US physician whistleblowers face intimidation and retaliation. Lancet Oncology 12, 727.

Greenwood BM (2004) The use of anti-malarial drugs to prevent malaria in the population of malaria-endemic areas. The American Journal of Tropical Medicine and Hygiene 70, 1-7.

Greenwood BM (2010) Anti-malarial drugs and the prevention of malaria in the population of malaria endemic areas. Malaria Journal 9(3 Suppl), S2.

Gutiérrez LA, Naranjo NJ, Cienfuegos AV et al. (2009) Population structure analyses and demographic history of the malaria vector Anopheles albimanus from the Caribbean and the Pacific regions of Colombia. Malaria Journal 19, 259.

Hall AP, Doberstyn EB, Karnchanachetanee C et al. (1977) Sequential treatment with quinine and mefloquine or quinine and pyrimethamine-sulfadoxine for falciparum malaria. British Medical Journal 1, 1626-1628.

Harinasuta T, Bunnag D \& Wernsdorfer WH (1983) A phase II clinical trial of mefloquine in patients with chloroquine-resistant falciparum malaria in Thailand. Bulletin of the World Health Organization 61, 299-305.

Hill DR, Baird JK, Parise ME, Lewis LS, Ryan ET \& Magill AJ (2006) Primaquine: report from CDC expert meeting on malaria chemoprophylaxis I. American Journal of Tropical Medicine and Hygiene 75, 402-415.

Hood JE, Jenkins JW, Milatovic D, Rongzhu L \& Aschner M (2010) Mefloquine induces oxidative stress and neurodegeneration in primary rat cortical neurons. Neurotoxicology 31, $518-523$

Iacopino V \& Xenakis SN (2011) Neglect of medical evidence of torture in Guantánamo bay: a case series. PLoS Medicine 8, e1001027.

Karbwang J, Na Bangchange K, Thanavibul A, Back DJ \& Bunnag D (1992) Pharmacokinetics of mefloquine in the presence of primaquine. European Journal of Clinical Pharmacology 42, $559-560$.

Kaye J \& Leopold J (2011) KBR's foreign contractors at Guantanamo spared controversial anti-malaria drug given to detainees. Available at: http://www.truth-out.org/contractorstreatment-undercuts-pentagon-rationale-giving-guantanamo detainees-anti-malarial-drug681 (accessed 21 June 2012).

Kofi Ekue JM, Ulrich AM, Rwabwogo-Atenyi J \& Sheth UK (1983) A double-blind comparative clinical trial of mefloquine 
R. L. Nevin Administration of mefloquine to Guantánamo detainees

and chloroquine in symptomatic falciparum malaria. Bulletin of the World Health Organization 61, 713-718.

Lapras J, Vighetto A, Trillet M \& Garin JP (1989) [Transient disorders of memory after a malaria attack. Caused by mefloquine?]. Presse Médicale 18, 776.

LaRocque RC, Rao SR, Lee J et al. (2011) Global TravEpiNet: a national consortium of clinics providing care to international travelers-analysis of demographic characteristics, travel destinations, and pretravel healthcare of high-risk US international travelers, 2009-2011. Clinical Infectious Diseases 54, 455462.

Leopold J \& Kaye J (2010) Controversial Drug Given to All Guantanamo Detainees Akin to 'Pharmacologic Waterboarding'. Available at: http://www.truth-out.org/controversial-druggiven-all-guantanamo-detainees-amounted-pharmacologic-water boarding6558 (accessed 21 June 2012).

Magill AJ (2006) Malaria: diagnosis and treatment of falciparum malaria in travelers during and after travel. Current Infectious Disease Reports 8, 35-42.

Magill AJ, Cersovsky SB \& DeFraites RF (2011) CDC Health Information for International Travel 2012. Advising travelers with specific needs: special considerations for US military deployments. Available at: wwwnc.cdc.gov/travel/yellow book/2012/chapter-8-advising-travelers-with-specific-needs/ special-considerations-for-us-military-deployments.htm (accessed 21 June 2012).

Matisz CE, Naidu P, Shokoples SE et al. (2011) Post-arrival screening for malaria in asymptomatic refugees using real-time PCR. The American Journal of Tropical Medicine and Hygiene 84, 161-165.

Maugh TH (1977) Malaria drugs: new ones are available, but little used. Science 196, 415.

Miller JM, Boyd HA, Ostrowski SR et al. (2000) Malaria, intestinal parasites, and schistosomiasis among Barawan Somali refugees resettling to the United States: a strategy to reduce morbidity and decrease the risk of imported infections. The American Journal of Tropical Medicine and Hygiene 62, 115-121.

Milner E, McCalmont W, Bhonsle J et al. (2010) Anti-malarial activity of a non-piperidine library of next-generation quinoline methanols. Malaria Journal 9, 51.

Molina-Cruz A, de Mérida A, Mills K et al. (2004) Gene flow among Anopheles albimanus populations in Central America, South America, and the Caribbean assessed by microsatellites and mitochondrial DNA. The American Journal of Tropical Medicine and Hygiene 71, 350-359.

Nevin RL (2010) Mefloquine prescriptions in the presence of contraindications: prevalence among US military personnel deployed to Afghanistan, 2007. Pharmacoepidemiology and Drug Safety 19, 206-210.

Nevin RL (2012) Limbic encephalopathy and central vestibulopathy caused by mefloquine: a case report. Travel Medicine and Infectious Disease 10, 144-151.

Nevin RL, Pietrusiak PP \& Caci JB (2008) Prevalence of contraindications to mefloquine use among USA military personnel deployed to Afghanistan. Malaria Journal 7, 30.
Nosten F, McGready R, Looareesuwan S \& White NJ (2003) Editorial: maternal malaria: time for action. Tropical Medicine and International Health 8, 485-487.

Office of the Assistant Secretary of Defense for Health Affairs (OASDHA) (2009) Policy Memorandum on the Use of Mefloquine (Lariam $\left.{ }^{\circledR}\right)$ in Malaria Prophylaxis. Available at: http://www.health.mil/libraries/HA_Policies_and_Guidelines/ 09-017.pdf (accessed 21 June 2012).

Office of the Assistant Secretary of Defense for Health Affairs (OASDHA) (2012) Memorandum dated 17 January 2012, Subject: Service Review of Mefloquine Prescribing Practices. Available at: truth-out.org/files/Mefloquine-QA-Memo-JAN2012-(Signed).pdf (accessed 21 June 2012).

Oliver M, Simon F, de Monbrison F et al. (2008) [New use of primaquine for malaria]. Médecine et maladies infectieuses 38, 169-179.

Overbosch D, Schilthuis H, Bienzle U et al. (2001) Atovaquoneproguanil versus mefloquine for malaria prophylaxis in nonimmune travelers: results from a randomized, double-blind study. Clinical Infectious Diseases 33, 1015-1021.

Parikh R, Amole I, Tarpley M, Gbadero D, Davidson M \& Vermund SH (2010) Cost comparison of microscopy vs. empiric treatment for malaria in southwestern Nigeria: a prospective study. Malaria Journal 9, 371.

Patchen LC, Campbell CC \& Williams SB (1989) Neurologic reactions after a therapeutic dose of mefloquine. New England Journal of Medicine 321, 1415-1416.

Pearlman EJ, Doberstyn EB, Sudsok S, Thiemanun W, Kennedy RS \& Canfield CJ (1980) Chemosuppressive field trials in Thailand. IV. The suppression of Plasmodium falciparum and Plasmodium vivax parasitemias by mefloquine (WR 142,490, A 4-quinolinemethanol). American Journal of Tropical Medicine and Hygiene 29, 1131-1137.

Phares CR, Kapella BK, Doney AC et al. (2011) Presumptive treatment to reduce imported malaria among refugees from east Africa resettling in the United States. The American Journal of Tropical Medicine and Hygiene 85, 612-615.

Price R, Nosten F, Simpson JA et al. (1999) Risk factors for gametocyte carriage in uncomplicated falciparum malaria. The American Journal of Tropical Medicine and Hygiene 60, 1019-1023.

Rendi-Wagner P, Noedl H, Wernsdorfer WH, Wiedermann G, Mikolasek A \& Kollaritsch H (2002) Unexpected frequency, duration and spectrum of adverse events after therapeutic dose of mefloquine in healthy adults. Acta Tropica 81, 167-173.

Rouveix B, Bricaire F, Michon C et al. (1989) Mefloquine and an acute brain syndrome. Annals of Internal Medicine 110, $577-578$.

Scheinkman A, Williams M, McLean A, Ashkenas J \& Tse A (2012) The Guantánamo docket: a history of the detainee population. Available at http://projects.nytimes.com/ guantanamo (accessed 21 June 2012).

Scsepko MM (2002) West Nile virus: next stop GTMO? The Wire: Published in the interest of personnel assigned to JTF-160 and COM-NAV Base Guantanamo Bay, Cuba, 30 August, 10-11. 


\section{R. L. Nevin Administration of mefloquine to Guantánamo detainees}

Available at: http://upload.wikimedia.org/wikipedia/commons/ 1/19/The_Wire_Issue12v2.pdf (accessed 21 June 2012).

Shane L (2011) Experts: DOD malaria drug policy for detainees is malpractice. Available at: http://www.stripes.com/experts-dodmalaria-drug-policy-for-detainees-is-malpractice-1.132623 (accessed 21 June 2012).

Sirima SB, Cotte AH, Konaté A et al. (2006) Malaria prevention during pregnancy: assessing the disease burden one year after implementing a program of intermittent preventive treatment in Koupela District, Burkina Faso. The American Journal of Tropical Medicine and Hygiene 75, 205-211.

Slutsker L, Tipple M, Keane V, McCance C \& Campbell CC (1995) Malaria in east African refugees resettling to the United States: development of strategies to reduce the risk of imported malaria. The Journal of Infectious Diseases 171, 489-493.

Stauffer WM, Weinberg M, Newman RD et al. (2008) Predeparture and post-arrival management of $P$. falciparum malaria in refugees relocating from sub-Saharan Africa to the United States. The American Journal of Tropical Medicine and Hygiene 79, 141-146.

Strauch S, Jantratid E, Dressman JB et al. (2011) Biowaiver monographs for immediate release solid oral dosage forms: mefloquine hydrochloride. Journal of Pharmceutical Sciences 100, 11-21.

Tagbor H, Bruce J, Agbo M, Greenwood B \& Chandramohan D (2010) Intermittent screening and treatment versus intermittent preventive treatment of malaria in pregnancy: a randomised controlled non-inferiority trial. PLOS ONE 5, e14425.

Tin F, Hlaing N \& Lasserre R (1982) Single-dose treatment of falciparum malaria with mefloquine: field studies with different doses in semi-immune adults and children in Burma. Bulletin of the World Health Organization 60, 913-917.

Toovey S (2009) Mefloquine neurotoxicity: a literature review. Travel Medicine and Infectious Disease 7, 2-6.
Trenholme CM, Williams RL, Desjardins RE et al. (1975) Mefloquine (WR 142,490) in the treatment of human malaria. Science 190, 792-794.

United Nations Development Programme (UNDP), World Bank \& World Health Organization (1983) Development of mefloquine as an antimalarial drug. Bulletin of the World Health Organization 61, 169-178.

von Seidlein L \& Greenwood BM (2003) Mass administrations of antimalarial drugs. Trends in Parasitology 19, 452-460.

Wallace MR, Sharp TW, Smoak B et al. (1996) Malaria among United States troops in Somalia. American Journal of Medicine 100, 49-55.

White NJ (2005) Intermittent presumptive treatment for malaria. PLoS Medicine 2, e3.

Whitman TJ, Coyne PE, Magill AJ et al. (2010) An outbreak of Plasmodium falciparum malaria in U.S. Marines deployed to Liberia. The American Journal of Tropical Medicine and Hygiene 83, 258-265.

World Health Organization (WHO) (1989) Central nervous system reactions related to the antimalarial drug, mefloquine, WHO/MAL/89/1054. Available at: http://whqlibdoc.who.int/ malaria/WHO_MAL_89.1054.pdf (accessed 21 June 2012).

World Health Organization (WHO) (2001) The use of antimalarial drugs: report of an informal consultation, 13-17 November 2000. Available at: http://whqlibdoc.who.int/hq/ 2001/WHO_CDS_RBM_2001.33.pdf (accessed 21 June 2012).

World Health Organization (WHO) (2004) A strategic framework for malaria prevention and control during pregnancy in the African Region. Available at: http://whqlibdoc.who.int/afro/ 2004/AFR_MAL_04.01.pdf (accessed 21 June 2012).

World Health Organization (WHO) (2010) Guidelines for the Treatment of Malaria, 2nd edn. Available at: http://whqlib doc.who.int/publications/2010/9789241547925_eng.pdf (accessed 21 June 2012).

Corresponding Author Remington L. Nevin, Department of Preventive Medicine, Bayne-Jones Army Community Hospital, Ft. Polk, LA 71459, USA. E-mail: remington.nevin@us.army.mil 